g. The study group was divided into three subgroups according to gestational weeks ( $<28 \mathrm{wk}, \mathrm{n}=79 ; 28-316 / 7 \mathrm{wk}, \mathrm{n}=204$; 32-33 6/7 wk, $n=145$ ). Twenty five percent of the infants were small for gestational age (SGA). Mean age at first thyroid function evaluation was $18.3 \pm 12.5$ days. Mean fT4 levels were $12.0 \pm 3.1,14.1 \pm 3.3$ and $17.7 \pm 3.9 \mathrm{pmol} / \mathrm{L}$ in three subgroups, respectively and significantly lower in infants $<28$ weeks. In all subgroups SGA infants had lower fT4 levels, but it was significantly lower in only 28-31 6/7 and $32-336 / 7$ weeks but not in $<28$ weeks subgroup. Overall, the prevalence of hypothyroxinemia and hypothyroidism were $25 \%$ and $0.8 \%$, respectively in the first evaluation. $17.6 \%$ of infants $<28$ weeks had hypothyroxinemia $(n=13)$ and all of them were treated. In the total group levothyroxine treatment was given to 51 (11.9\%) infants. Mean treatment period was $1.6 \pm 1.2$ years.

Conclusion Free T4 levels were lower in the early gestational age subgroups. SGA infants had lower fT4 levels.

\section{PREVALENCE OF SENSORINEURAL HEARING LOSS IN PATIENTS WITH CONGENITAL HYPOTHYROIDISM}

doi:10.1136/archdischild-2012-302724.0652

'F Saffari, ${ }^{2} \mathrm{MH}$ Ababafha. 'Pediatrics, Oazvin University of Medical Sciences; ${ }^{2}$ Oazvin University of Medical Sciences, Oazvin, Iran

Background and Aims Congenital hypothyroidism is mainly diagnosed through neonatal screening program. Normal physical and mental development can be maintained with pertinent replacement therapy. One of the associated abnormalities in these patients is the sensorineural hearing defect, which has a prevalence of about $20 \%$ according to relevant references. The purpose of this study was to obtain the prevalence of sensorineural hearing loss in children with congenital hypothyroidism identified in the screening program in Qazvin, Iran.

Methods All patients afflicted with congenital hypothyroidism identified in the screening program (in Qazvin, Iran) were enrolled in this study. They were both under observed and hormonal replacement therapy by referral Endocrine Diseases Clinic and auditory brainstem responses test (ABR) was performed for all subjects.

Results Of 169 patients with congenital hypothyroidism, 42.3\% were female. The prevalence of sensorineural hearing loss was $5.3 \%$ (6 male, 2 female). Statistical analysis did not reveal any significant difference between the prevalence of sensorineural hearing loss with other variables of the study.

Conclusions A remarkable difference was observed between the results of our study with those stated in the references. Normal sensorineural hearing can be maintained with pertinent replacement therapy.

\section{PLACENTAL WEIGHT: RELATION TO MATERNAL WEIGHT AND GROWTH PARAMETERS AT BIRTH AND DURING CHILDHOOD}

doi:10.1136/archdischild-2012-302724.0653

A Soliman, M Eldabbagh, K Zahreldin, A Elawwa. Pediatrics, Hamad Medical Center, Doha, Oatar

Background Human growth is a continuous process. Studies defining placental effect on growth focus on discrete time points (e.g., birth), overlooking the conditional nature of the process.

Material and Methods Two hundred mothers who gave birth at term after an uncomplicated singleton pregnancy were studied using conditional analysis. Placental weight, infant length (BL), weight $(\mathrm{BW})$, and head circumference $(\mathrm{HC})$ were obtained at birth and during childhood period ( $4.5+/-2$ years) of age. Placental weight was correlated with growth parameters of the child at birth and during childhood.
Results At birth, placental weight was correlated significantly with maternal weight $(\mathrm{r}=0.21, \mathrm{p}=0.031)$, infant $\mathrm{BW}(\mathrm{r}=0.71, \mathrm{r}$ $<0.001)$, BMISDS( $\mathrm{r}=0.589, \mathrm{p}<0.001)$, LSDS (0.567, $\mathrm{p}<0.001)$, and $\mathrm{HC}(\mathrm{r}=0.699, \mathrm{p}<0.001)$. During childhood, placental weight was correlated with BMI SDS ( $r=0.296, p=0.002), \mathrm{HtSDS}=(\mathrm{r}=0.254$, $\mathrm{p}=0.009)$. Length SDS at birth was correlated significantly with HtSDS during childhood $(r=0.445, p<0.001)$.

Conclusion Placental weight is a good pointer of birth size (weight, length and HC) and may help forecast childhood growth.

\section{THE DIFFERENTIAL-DIAGNOSTIC FEATURES OF THELARCHE SYNDROME IN GIRLS}

doi:10.1136/archdischild-2012-302724.0654

V Buinitskaya, A Solntsava, 0 Zagrebaeva. Belarusian State Medical University, Minsk, Belarus

Aim To determine the most significant criteria in the diagnosis of true precoicois puberty and premature thelarche.

Methods 68 girls were analyzed in the endocrinological department in Minsk over 2003-2011 yrs. Group 1(G1) - girls with isolated thelarche (IT) (58 (85.3\%); group 2(G2) - with true precoicois puberty (TPP) (10 (14.7\%). Ultrasound $(\mathrm{u} / \mathrm{s})$ organs of the small pelvis, bone age, the levels of hormones (follicle-stimulating hormone $(\mathrm{FSH})$, luteinizing hormone (LH), estradiol (E2); gonadotropinreleasing hormone analogue $(\mathrm{GRH})$ stimulating test were conducted to all patients. Results were processed using the Statistica 6.1.

Results Breast development in G1: stages on Tanner 2 (84.3\%), 3 (15.7\%); G2: Tanner 2 (80\%), 3 (20\%). The onset of thelarche G1 $1.2 \pm 0.3$ yrs, G2 $5.3 \pm 0.77(\mathrm{p}=0.2)$. Bone age $(\mathrm{BoA}) /$ biological age $(\mathrm{Bia})$ G1 $0.63 \pm 0.08$ (< 1yrs), G2 3.3 \pm 0.01 . Uterus length G1 28.1 \pm 0.83 $(<35 \mathrm{~mm}), \mathrm{G} 235.4 \pm 2.9(\mathrm{p}=0.1)$. There was an excess of prepubertal ovaries norm ( $>0.2 \mathrm{ml})$ G1 $65 \%$, G2 $48 \%$ with the presence of follicules G1 20\%, G2 100\%. Basal FSH levels G1 4.73 \pm 0.52 (1.8-10.5 IU/L), G2 4.25 \pm 0.87 ( $p=0.3$ ); LH G1 0.76 \pm 0.13 (1-10 IU/L), G2 2 \pm 0.8 $(\mathrm{p}=0.15) ;$ E2 G1 $0.12 \pm 0.02(<0.5 \mathrm{ng} / \mathrm{ml}), \mathrm{G} 20.14 \pm 0.05(\mathrm{p}=0.08)$. There was a pubertal excess of LH levels in G2 (39.4 $20.4 \mathrm{IU} / \mathrm{L})$ by conducting GRH stimulating test.

Conclusions The differential diagnosis between TPP and IT are: advance $\mathrm{BoA}$ to $\mathrm{BiA}$, the excess of uterus length by $\mathrm{u} / \mathrm{s}$ and $\mathrm{E} 2$ levels, excess of LH levels by conducting stimulating test with GRH (which is the most important feature).

\section{GENDER PECULIARITIES OF THE COURSE OF GRAVES- BASEDOW DISEASE IN CHILDREN}

doi:10.1136/archdischild-2012-302724.0655

K Konchyts, A Solntsava, 0 Zagrebaeva. Paediatrics, Belarussian State Medical University, Minsk, Belarus

Aim To determine gender peculiarities of the course of GravesBasedow disease (GBD) in children depending on the sex and stage of puberty.

Methods We analyzed retrospectively 28 children with GBD in the endocrinological department of University hospital over the 2011 year (boys(B)/girls(G) 3/25, mean \pm SD age $13.15 \pm 3.03$ yrs). We conducted additional division on the subgroups of early (Tanner 2-3) and late (Tanner 4-5) puberty.

Results $67.8 \%$ children had complains (B losing weight $(66.7 \%)$; G weakness $(32 \%)$, heartbeat $(24 \%)$. Family history wasn't burdened in $33.3 \%$ B and $64 \%$ G. Relatives with diabetes mellitus type 1 was in $7.1 \%$ G; thyroid diseases $-33.3 \%$ B and $28 \%$ G; other endocrinopathies $33.3 \% \mathrm{~B}, 12 \% \mathrm{G}$. There was a tendency of more early manifestation GBD in G 12.94 \pm 3.07 yrs (B 14.86 \pm 2.42 yrs) ( $\Varangle>0.05)$. The onset of GBD was mainly in late puberty regardless of gender. There was lower TSH 0,085 $\pm 0.13(0.23-3.4 \mu \mathrm{IU} / \mathrm{l})$ and higher free T4 $62.13 \pm 34.34(10-23.2 \mathrm{pmol} / \mathrm{l})$ levels in B (G $0.12 \pm 0.2$ and 